\title{
New tendency of Chinese container port system: 1998-2010
}

\author{
Kunyou Pan · Youhui Cao $\cdot$ Shuangbo Liang • \\ Hongyan Wei
}

Published online: 26 September 2013

(C) The Author(s) 2013. This article is published with open access at Springerlink.com

\begin{abstract}
By Hirschman-Herfindahl Index, the paper measures the spatial structure transformation of the Chinese container port system from the perspective of cargo flow in recent 13 years. It indicates that the spatial structure of container port system enters into "the challenge of the periphery" phase as a whole, the decentralization of container flow become the mainstream tendency of the spatial variation of China's container port system; on the other hand, the spatial structure of container port system shows different characteristic in seven port regions, such as low-level equilibrium, single-gateway, multi-gateway and so on. It is a fact that multigateway port region of container port system has formed in Yangtze River Delta and Pearl River Delta region. Economic and foreign trade development,
\end{abstract}

K. Pan $(\bowtie) \cdot$ Y. Cao $\cdot$ S. Liang

Nanjing Institute of Geography and Limnology, CAS,

Nanjing 210008, China

e-mail: pankunyou@163.com

K. Pan

University of Chinese Academy of Sciences,

Beijing 100039, China

K. Pan $\cdot$ H. Wei

School of Economics and Management, Yancheng Institute of Technology, Yancheng 224051, China

H. Wei

School of Geographic Sciences, Nanjing Normal

University, Nanjing 210097, China government macro-control and policy guidance, challenge of the periphery, network expansion of the terminal operators and shipping liners are the main driving forces for these new phenomena.

Keywords Container port system - Multi-port gateway $\cdot$ Hirshmann-Herfindahl Index $\cdot$ China

\section{Introduction}

Literature reviews on port geographical research show that the study on port system development has been the hotspot of the Port Geography field. Large amount of papers on the formation and evolution of port system were published in the relevant journals from 1963 to 2008 (Ducruet et al. 2009), among which Taaffe model and Hayuth model would be the representative achievements. With the continuous development of transportation network in the hinterland, Taaffe et al. (1963) found that cargo flow of the port system gradually tends to concentrate by the empirical study on spatial interaction process of Ghanaian and Nigerian maritime ports, and then summarized it as six stages, such as the scattered ports, penetration lines and port concentration, development of feeders, beginnings of interconnection, complete interconnection, and emergence of high priority "main streets". Since then, Slack (1990) added the seventh stage to Taaffe model, he thought 
that the traffic volume of transport corridor would continue to gather and the extra nodes would be eliminated with the development of the intermodal system. In 1981, basing on the analysis of American container port system, Hayuth (1981) thought that it went through five stages, such as precondition for change, initial container port development, diffusionconsolidated and port concentration, the load center, the challenge of the periphery. In the first four phases, the spatial structure evolution of the container port system which tended to centralize was in accordance with Taaffe model. But thereafter, with the intensification of diseconomies of scale and other limiting factors, container flow began to decentralize and produced peripheral challenge phenomenon. This phenomenon has aroused widely attention among later scientists, thus Hayuth model has been continually revised and improved (Hayuth 1988; Slack and Wang 2002; Notteboom 2005; Frémont and Soppé 2007). Entering the twenty-first century, especially since the financial crisis, the strengthening of trade connection between Far East and Europe, the expansion of the service network of large shipping companies and the restructuring of the international shipping route have leaded to the formation of multiport gateway regions in European like Genoa-La Spezia-Livorno, Hamburg-Bremen, Antwerp-Zeebrugge and Rotterdam-Amsterdam (Notteboom 2010). This spatial transformation is the same in the United States, South Korea and Singapore, as Singapore-Tanjung Pelapas (Tongzon 2006), BusanGwangyang (Yeo and Cho 2007), Seattle-Long Beach (O'Connor 2010). The fifth stage of Hayuth Model has been verified in many countries and regions around the world, and what about China?

China is advantaged with a long coastline reaching from the Bohai Sea to the Beibu Gulf. The Chinese port system cannot be considered as a homogenous set of ports. It is made up of established large ports as well as a whole series of medium-sized to smaller ports each with specific characteristics in terms of hinterland markets served, commodities handled and location qualities. This unique blend of different port types and sizes combined with a vast economic hinterland shapes port hierarchy and competition in the region. A number of port studies have dealt with port competition and development in Chinese regions or in individual Chinese ports. Cullinane et al. (2005),
Wang and Oliver (2007a), Comtois and Dong (2007), Wang and Ducruet (2012) are among the papers discussing container port competition in the Yangtze River Delta. The Pearl River Delta gateway ports and transshipment hubs also received a lot of attention in recent years (see e.g. Wang and Slack (2000), Song (2002), Wang and Olivier (2007b), Wang et al. (2012), Liu et al. (2013)).The mentioned port studies provide insight into the competitive dynamics in the respective regions, but lack a Chinese-wide dimension.

Since 1998, being driven by rapid economic development, Chinese container throughput has grew by 26 million TEU in 1998 to 162 million TEU (including Hong Kong) in 2010, the proportion of the world's total container throughput increased by 8.59-27.88\%, which has become the world's largest container port system unit. In this context, the "challenge of the periphery" which is characterized by container flow decentralization is in our country? Does its spatial structure present a new feature? If present, what is the mechanism of this process?

\section{Ports and port ranges}

Ports

China is a large country with both mainland and sea, owning $18,000 \mathrm{~km}$ of continental coastline and $14,000 \mathrm{~km}$ of island shoreline, and it has more than 150 coastal ports, including nearly 50 container ports. We select 39 container ports which container handling capacity surpassing 10,000 TEU in 1998 as the study object in this research (Fig. 1).

Since 1998, the container throughput of sample ports has increased by 26 million TEU in 1998 to 162 million TEU in 2010, an average growth rate of $16.47 \%$ is much higher than the growth rate of $10.73 \%$ of the world, and China has become the fastest growing country in the world. Especially since the financial crisis, the sample ports have remain nearly double-digit growth rate in the case of the container throughput of American and European major port substantially reducing (Fig. 2). The increasing velocity of Tianjin, Qingdao, Shanghai, Xiamen, Guangzhou, Shenzhen ports are more than $20 \%$, some of them have reach $30 \%$, such as Suzhou and Ningbo ports. 


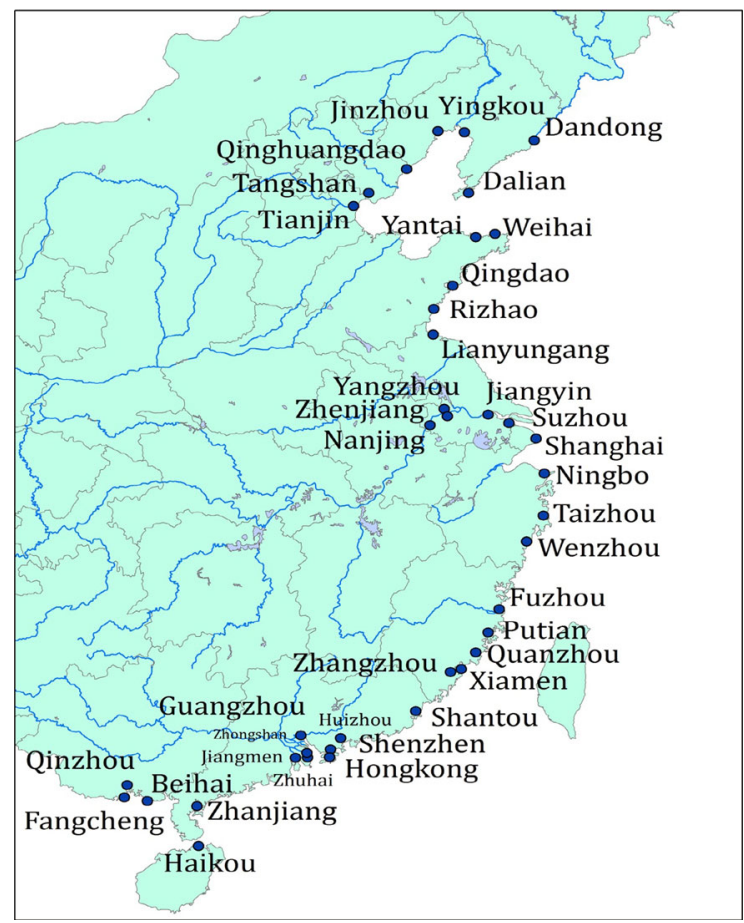

Fig. 1 The sample port in china

Port ranges

Chinese Ministry of Transport issued "Chinese Coastal port layout plan" in 2006. Basing on economic development and features of different regions, relations between ports within the same region, and economic rationality of major cargo transportation, the coastal ports were subdivided into five port ranges, such as Bohai Rim, Yangtze River Delta, Southeast coast, Pearl River Delta and Southwest coast. The Bohai Rim port range was composed of Liaodong Peninsula, Bohai Sea West Bank and Shandong Peninsula, which served mainly social and economic development of northern coastal and inland areas. So here the container port system is divided into seven parts, like Liaodong Peninsula port range, Bohai Sea West Bank port range, Shandong Peninsula port range, Yangtze River Delta port range, Southeast coastal port range, Pearl River Delta port range and Southwest coastal port range (Table 1). Needing to add six points here are as follows.

- Viewing the Southwest coastal and Southeast coastal port range as two independent port system on account of huge potential for economic development.

- Hong Kong is assigned to the Pearl River Delta Port System so that it can ensure the integrity of the Pearl River Delta Container Port System.

- Lianyungang is arranged to the Yangtze River Delta port range because of the provincial government and its main economic connection.

- Ningbo Port contains Zhoushan Port since 2006.

- Suzhou Port contains Taicang, Zhangjiagang and Changshu port.
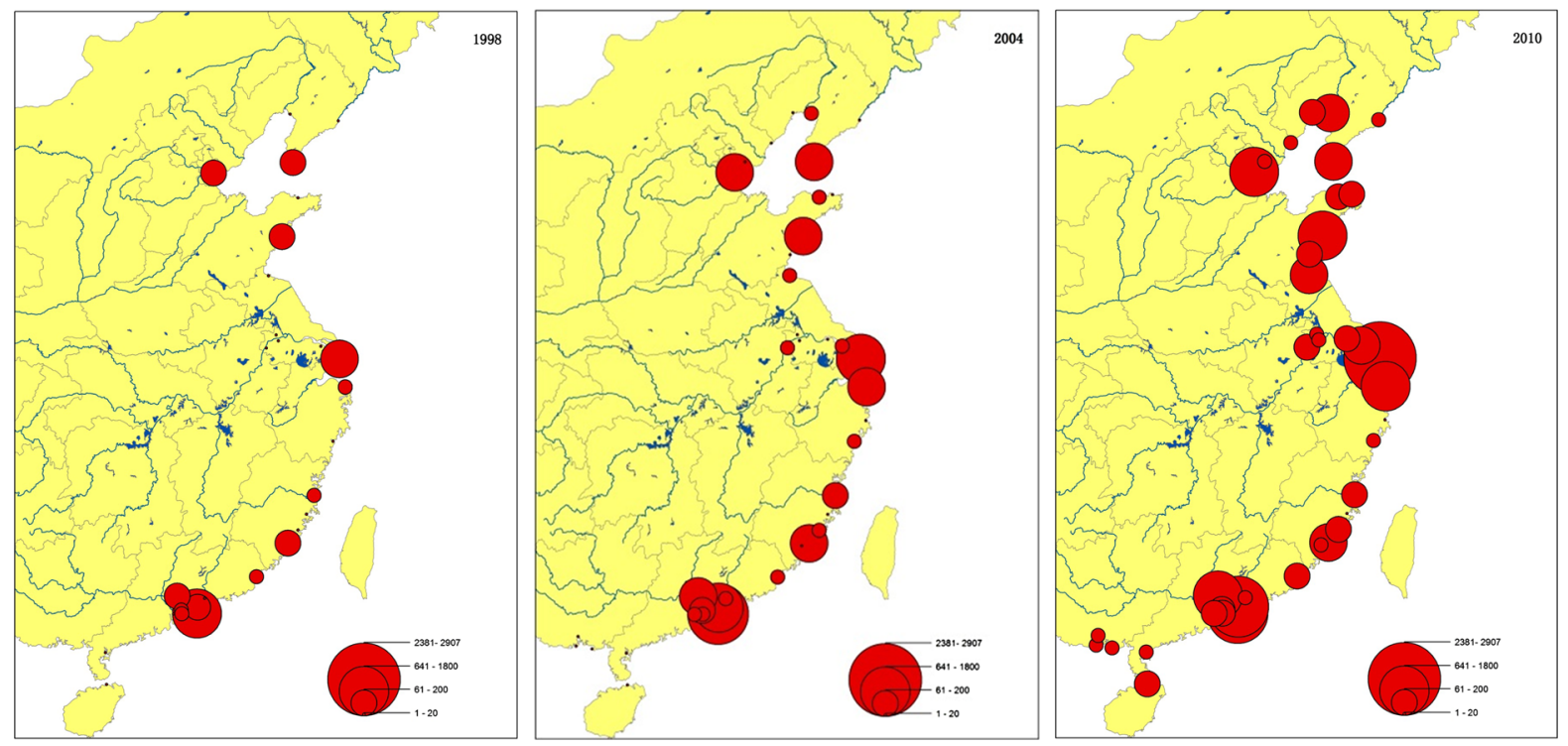

Fig. 2 Evolution of Chinese port hierarchy, 1998-2010 
Table 1 The ports and port ranges in China

\begin{tabular}{|c|c|c|}
\hline \multicolumn{2}{|c|}{ Port ranges } & \multirow{2}{*}{$\begin{array}{l}\text { Main ports and Hinterland } \\
\text { Dandong, Dalian, Yingkou, Jinzhou; } \\
\text { serving mainly three provinces in } \\
\text { the northeast of China and eastern } \\
\text { part of Inner Mongolia. }\end{array}$} \\
\hline $\begin{array}{r}\text { Bohai } \\
\text { Rim }\end{array}$ & $\begin{array}{l}\text { Liaodong } \\
\text { Peninsula }\end{array}$ & \\
\hline & $\begin{array}{l}\text { Bohai Sea } \\
\text { West Bank }\end{array}$ & $\begin{array}{l}\text { Tianjin, Qinhuangdao, Tangshan; } \\
\text { serving mainly Beijing, Tianjin and } \\
\text { North China. }\end{array}$ \\
\hline & $\begin{array}{l}\text { Shandong } \\
\text { Peninsula }\end{array}$ & $\begin{array}{l}\text { Qingdao, Yantai, Rizhao, Weihai; } \\
\text { serving mainly Shandong Peninsula } \\
\text { region and its west region. }\end{array}$ \\
\hline \multicolumn{2}{|c|}{ Yangtze River Delta } & $\begin{array}{l}\text { Shanghai, Ningbo, Suzhou, } \\
\text { Lianyungang, Nanjing, Zhenjiang, } \\
\text { Yangzhou, Jiangyin, Taizhou, } \\
\text { Wenzhou; serving mainly Yangtze } \\
\text { River Delta and areas along the } \\
\text { Yangtze River. }\end{array}$ \\
\hline \multicolumn{2}{|c|}{ Southeast coast } & $\begin{array}{l}\text { Fuzhou, Xiamen, Quanzhou, } \\
\text { Zhangzhou, Putian; serving mainly } \\
\text { Fujian, Jiangxi and other inland } \\
\text { provinces, meeting the demand of } \\
\text { three direct links to Taiwan. }\end{array}$ \\
\hline \multicolumn{2}{|c|}{ Pearl River Delta } & $\begin{array}{l}\text { Hong Kong, Shenzhen, Guangzhou, } \\
\text { Zhuhai, Zhongshan, Shantou, } \\
\text { Huizhou, Jiangmen; strengthening } \\
\text { the exchanges between Guangdong, } \\
\text { inland areas and Hong Kong, } \\
\text { Macao. }\end{array}$ \\
\hline \multicolumn{2}{|c|}{ Southwest coast } & $\begin{array}{l}\text { Haikou, Beihai, Fangcheng, Qinzhou, } \\
\text { Zhanjiang;serving Chinese western } \\
\text { areas and providing transportation } \\
\text { support for Hainan's foreign trade. }\end{array}$ \\
\hline
\end{tabular}

Source "Chinese Coastal port layout plan" (China's Ministry of Transport 2006)

- Haikou and Fangcheng ports are the main transit hubs of the Chinese western areas, and considered within the same range.

\section{New dynamics in Chinese container port system}

Gernal discussion

With a total maritime container throughput of an estimated 162 million TEU in 2010, the Chinese container port system has become the busiest container port systems in the word. However, the growth rate has showed larger difference among seven port ranges in recently 13 years. The Pearl River Delta port range increased by 18.41 million
TEU in 1998 to 62.42 million TEU in 2010, the average growth rate of $10.71 \%$ is significantly lower than the national average rate, its absolute market share fell $38.48 \%$ from $69.84 \%$, but its absolute container throughput still ranked firstly and led the Yangtze River Delta port range of 9.07 million TEU. The rapid development of container throughput in the Yangtze River Delta region is another significant feature over the past decade of China's container port system, its container throughput has increased nearly 14-fold from 1998 to 2010 with an annual average growth rate of up to $24.40 \%$, and it is higher than the national average growth rate of 8.1 percentage points, the share of the country's container port system increased from $14.73 \%$ to $32.89 \%$, which was close to the Pearl River Delta port range. In addition, the growth rate of container throughput of the Liaodong Peninsula port range, Bohai Sea West Bank port range, Shandong Peninsula port range, Southeast coastal port range and Southwest coastal port range is also very significant, their growth rates have respectively reached $24.58,21.56,22.59$, 20.68 , and $30.93 \%$, and their market share have improve 3.08, 2.22, 3.87, 1.45 and 0.71 points (Table 2). Basing on the previous analysis, the barycenter of Chinese container port system has began to move toward northward in the past two decades, the first status of the southern ports range represented by Hongkong has being threatened, and the Yangtze River Delta port range represented by Shanghai has gradually become the center of the container port system in China and the Asia-Pacific region.

Decentralization: theme of container flow spatial structure

Before the twenty-first century, the centralized trend of Chinese coastal container port system has been confirmed (Cao et al. 2004). However, it has not a clear judgment whether the container flow decentralized or centralized within the recent 10 years. The Gini-index and Lorenz curve are two most common tools that measure spatial structure of port system, but they have some defect (Scherer 1980). Here, the Hirschman-Herfindahl Index (HHI) is used for analysis, and it is defined as. 
Table 2 Regional port performance in Chinese seaboard

\begin{tabular}{|c|c|c|c|c|c|}
\hline Region & 1998 & 2001 & 2004 & 2007 & 2010 \\
\hline \multicolumn{6}{|c|}{ Liaodong Peninsula port range } \\
\hline TEU (millions) & 0.69 & 1.48 & 2.99 & 6.45 & 9.65 \\
\hline$\%$ of total & 2.62 & 3.46 & 3.77 & 4.85 & 5.95 \\
\hline \multicolumn{6}{|c|}{ Bohai Sea West Bank port range } \\
\hline TEU (millions) & 1.03 & 2.03 & 3.92 & 7.60 & 10.70 \\
\hline$\%$ of total & 3.90 & 4.75 & 4.95 & 5.71 & 6.60 \\
\hline \multicolumn{6}{|c|}{ Shandong Peninsula port range } \\
\hline TEU (millions) & 1.33 & 1.33 & 1.33 & 1.33 & 1.33 \\
\hline$\%$ of total & 5.03 & 6.69 & 7.18 & 8.61 & 9.42 \\
\hline \multicolumn{6}{|c|}{ Yangtze River Delta port range } \\
\hline TEU (millions) & 3.89 & 8.44 & 20.56 & 41.70 & 53.34 \\
\hline$\%$ of total & 14.73 & 19.69 & 25.95 & 31.36 & 32.89 \\
\hline \multicolumn{6}{|c|}{ Southeast coastal port range } \\
\hline TEU (millions) & 0.96 & 1.97 & 4.26 & 7.13 & 9.13 \\
\hline$\%$ of total & 3.63 & 4.60 & 5.37 & 5.36 & 5.63 \\
\hline \multicolumn{6}{|c|}{ Pearl River Delta port range } \\
\hline TEU (millions) & 18.42 & 25.86 & 41.36 & 57.84 & 62.42 \\
\hline$\%$ of total & 69.84 & 60.36 & 52.19 & 43.49 & 38.48 \\
\hline \multicolumn{6}{|c|}{ Southwest coastal port range } \\
\hline TEU (millions) & 0.07 & 0.19 & 0.47 & 0.83 & 1.67 \\
\hline$\%$ of total & 0.25 & 0.45 & 0.59 & 0.63 & 1.03 \\
\hline
\end{tabular}

$H H I=\frac{\left(\sum_{i=1}^{n} T E U_{i j}^{2}\right) /\left(\sum_{i=1}^{n} T E U_{i j}\right)^{2}-\frac{1}{n}}{1-\frac{1}{n}}$

With $\mathrm{TEU}_{\mathrm{ij}}$ equal to the container throughput in TEU of port $i$ and $n$ represents the number of ports in the $\mathrm{j}$ container port system. $0<\mathrm{HHI}<1$, higher index means a more concentrated port system. HHI is calculated as follows (Fig. 3).
The calculated result of HHI shows that decentralization has become the mainstream tendency of container flow in Chinese container port system. In 1998-2010, HHI has been fallen from 0.31 to 0.08 , which it is a larger decline in 1998-2005 and then enters a gentle decline period in 2006-2010. It shows that the container throughput of periphery port has been rapid growth before 2006. But it must be noted that the centralized level of the port system is not high, and the HHI has been still below 0.1 since 2006 (Fig. 3).

From the container port range, the HHI of seven port regions has shown a decline in varying degrees since 1998-2010, it is consistent with the country as a whole. However, Bohai Sea West Bank and Shandong Peninsula port ranges began to disperse under the background of high centralized levels of container flow, the decentralized speed of Liaodong Peninsula port range ranks first, the decentralization of southwest coastal port range is ongoing in the context of unobvious centralization for underdeveloped economic level. This space transformation can be reflected by market cumulative percentages of ports in Chinese coastland, the Share of top 1, top 3, top 5 and top 10 respectively decreased from $55,74,83$ and 94 to $18,46,62$ and 85 (Table 3).

Emergence: multi-port gateway spatial structure

In 2010, the container throughput of Tianjin, Qingdao, Shanghai, Ningbo, Hong Kong, Shenzhen and Guangzhou exceeds 10 million TEU, six except Qingdao ports enter the world top ten (Table 4). Specifically,
Fig. 3 The HHI of different container port systems during 1998-2010

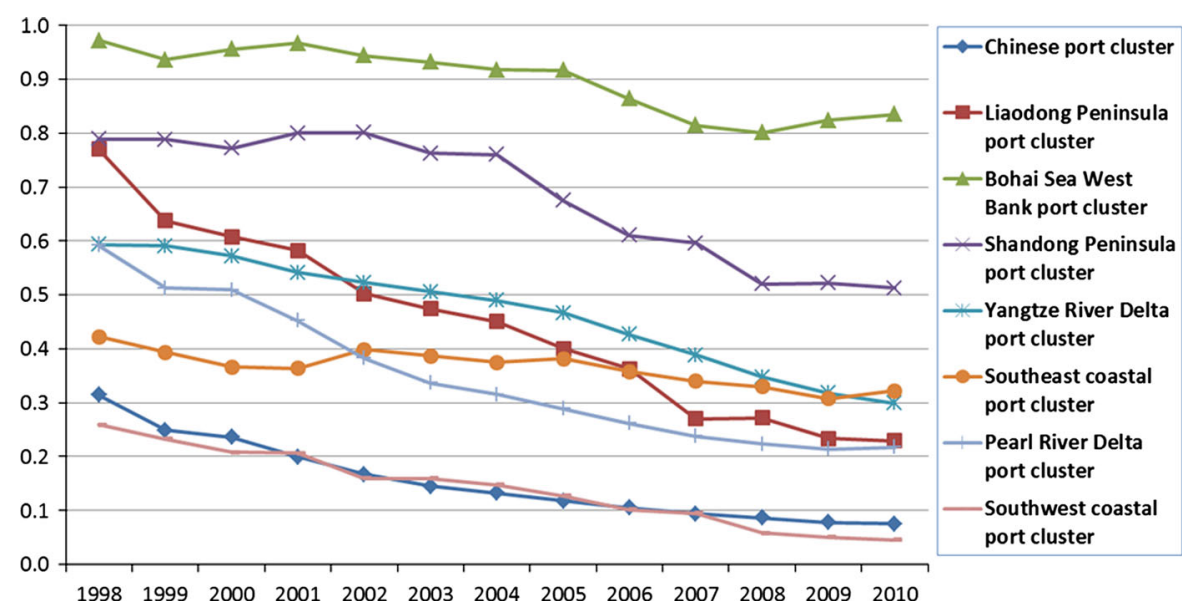


Table 3 Container throughput of top 10 container ports in China

\begin{tabular}{|c|c|c|c|c|c|c|c|c|c|c|}
\hline \multirow[t]{2}{*}{$\mathrm{R}$} & \multicolumn{10}{|c|}{ In 10,000 TEU } \\
\hline & \multicolumn{2}{|l|}{1998} & \multicolumn{2}{|l|}{2001} & \multicolumn{2}{|l|}{2004} & \multicolumn{2}{|l|}{2007} & \multicolumn{2}{|l|}{2010} \\
\hline 1 & Hong Kong & 1458 & Hong Kong & 1780 & Hong Kong & 2198 & Shanghai & 2615 & Shanghai & 2907 \\
\hline 2 & Shanghai & 307 & Shanghai & 634 & Shanghai & 1456 & Hong Kong & 2388 & Hong Kong & 2363 \\
\hline 3 & Shenzhen & 195 & Shenzhen & 508 & Shenzhen & 1362 & Shenzhen & 2110 & Shenzhen & 2251 \\
\hline 4 & Qingdao & 121 & Qingdao & 264 & Qingdao & 514 & Qingdao & 946 & Ningbo & 1314 \\
\hline 5 & Tianjin & 102 & Tianjin & 201 & Ningbo & 401 & Ningbo & 943 & Guangzhou & 1212 \\
\hline 6 & Guangzhou & 85 & Guangzhou & 163 & Tianjin & 381 & Guangzhou & 926 & Qingdao & 1201 \\
\hline 7 & Xiamen & 65 & Xiamen & 129 & Guangzhou & 331 & Tianjin & 710 & Tianjin & 1009 \\
\hline 8 & Dalian & 63 & Ningbo & 121 & Xiamen & 287 & Xiamen & 463 & Xiamen & 582 \\
\hline 9 & Ningbo & 35 & Dalian & 121 & Dalian & 221 & Dalian & 382 & Dalian & 524 \\
\hline 10 & Zhongshan & 33 & Zhongshan & 55 & Zhongshan & 92 & Lianyungang & 200 & Lianyungang & 387 \\
\hline \multicolumn{2}{|c|}{ Top 10} & 2464 & Top 10 & 3976 & Top 10 & 7243 & Top 10 & 11684 & Top 10 & 13750 \\
\hline \multicolumn{2}{|c|}{ Total port } & 2634 & Total port & 4275 & Total port & 7910 & Total port & 13271 & Total port & 16187 \\
\hline \multicolumn{2}{|c|}{ Share top 1} & $55 \%$ & Share top 1 & $42 \%$ & Share top 1 & $28 \%$ & Share top 1 & $20 \%$ & Share top 1 & $18 \%$ \\
\hline \multicolumn{2}{|c|}{ Share top 3} & $74 \%$ & Share top 3 & $68 \%$ & Share top 3 & $63 \%$ & Share top 3 & $54 \%$ & Share top 3 & $46 \%$ \\
\hline \multicolumn{2}{|c|}{ Share top 5} & $83 \%$ & Share top 5 & $79 \%$ & Share top 5 & $75 \%$ & Share top 5 & $68 \%$ & Share top 5 & $62 \%$ \\
\hline \multicolumn{2}{|c|}{ Share top 10} & $94 \%$ & Share top 10 & $93 \%$ & Share top 10 & $92 \%$ & Share top 10 & $88 \%$ & Share top 10 & $85 \%$ \\
\hline
\end{tabular}

Source Own complication

Table 4 The container throughput of the top 10 ports in the word, 1998-2010

\begin{tabular}{|c|c|c|c|c|c|c|c|c|c|c|}
\hline \multirow[t]{2}{*}{$\mathrm{R}$} & \multicolumn{10}{|c|}{ In 10,000 TEU } \\
\hline & 1998 & & 2001 & & 2004 & & 2007 & & 2010 & \\
\hline 1 & Singapore & 1510 & Hong Kong & 1780 & Hong Kong & 2198 & Singapore & 2790 & Shanghai & 2907 \\
\hline 2 & Hong Kong & 1458 & Singapore & 1552 & Singapore & 2060 & Shanghai & 2615 & Singapore & 2843 \\
\hline 3 & Kaohsiung & 627 & Busan & 791 & Shanghai & 1456 & Hong Kong & 2388 & Hong Kong & 2363 \\
\hline 4 & Rotterdam & 603 & Kaohsiung & 754 & Shenzhen & 1362 & Shenzhen & 2110 & Shenzhen & 2251 \\
\hline 5 & Busan & 574 & Shanghai & 634 & Busan & 1143 & Busan & 1327 & Busan & 1428 \\
\hline 6 & Long Beach & 409 & Rotterdam & 609 & Kaohsiung & 917 & Rotterdam & 1079 & Ningbo & 1314 \\
\hline 7 & Hamburg & 355 & Los Angeles & 518 & Rotterdam & 828 & Dubai & 1065 & Guangzhou & 1212 \\
\hline 8 & Antwerp & 327 & Shenzhen & 508 & Los Angeles & 732 & Kaohsiung & 1026 & Qingdao & 1201 \\
\hline 9 & Los Angeles & 320 & Hamburg & 469 & Hamburg & 700 & Hamburg & 990 & Dubai & 1150 \\
\hline 10 & Shanghai & 307 & Long Beach & 446 & Dubai & 643 & Qingdao & 946 & Rotterdam & 1110 \\
\hline
\end{tabular}

Shanghai-Ningbo, Hong Kong-Shenzhen-Guangzhou are located in the same region.

Hong Kong has been a city of commence and a gateway to China since the late nineteenth century (Wang and Cheng 2010). As a British-colonized citystate, Hong Kong adopted a generally laissez-faire policy and chose not to cater to any industry that required long-term commitment. As a result, laborintensive manufacturing industries were established and supported by a port that was the first to be containerized among a few Asian cities in the early 1970s. The port of Hong Kong was able to reap the benefits of China's industrialization (Wang 1998). Lacking any deep-water ports with modern containerhandling infrastructures, the goods were transshipped at Hong Kong from trucks, river barges and coastal shipping. Hong Kong became a massive container transshipment center. However, it started to lose its 
Fig. 4 Container throughput comparison: Hong Kong, Shenzhen and Guanghzou

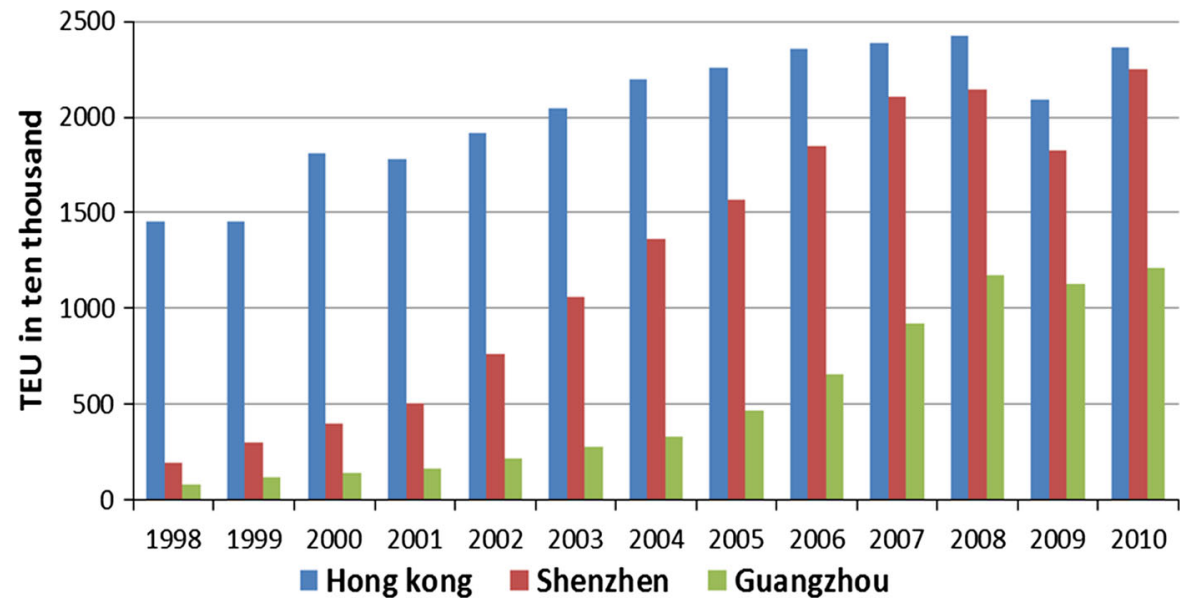

Table 5 The container throughput and percentage of main ports in six regions during 1998-2010

\begin{tabular}{|c|c|c|c|c|c|}
\hline \multicolumn{6}{|l|}{ In 10,000 TEU } \\
\hline \multirow[t]{2}{*}{ Port systems } & \multirow[t]{2}{*}{ Main ports } & \multicolumn{2}{|l|}{1998} & \multicolumn{2}{|l|}{2010} \\
\hline & & TEU & $\%$ & TEU & $\%$ \\
\hline $\begin{array}{l}\text { Liaodong Peninsula } \\
\text { port range }\end{array}$ & Dalian & 63 & 91 & 524 & 54 \\
\hline $\begin{array}{l}\text { Bohai Sea West Bank } \\
\text { port range } r\end{array}$ & Tianjin & 102 & 99 & 1009 & 94 \\
\hline $\begin{array}{l}\text { Shandong Peninsula } \\
\text { port range }\end{array}$ & Qingdao & 121 & 91 & 1201 & 79 \\
\hline \multirow{2}{*}{$\begin{array}{l}\text { Yangtze River Delta } \\
\text { port range }\end{array}$} & Shanghai & 307 & 79 & 2907 & 55 \\
\hline & Ningbo & 35 & 9 & 1314 & 25 \\
\hline $\begin{array}{l}\text { Southeast coastal port } \\
\text { range }\end{array}$ & Xiamen & 65 & 68 & 582 & 64 \\
\hline \multirow[t]{3}{*}{$\begin{array}{l}\text { Pearl River Delta port } \\
\text { range }\end{array}$} & $\begin{array}{l}\text { Hong } \\
\text { Kong }\end{array}$ & 1458 & 79 & 2363 & 38 \\
\hline & Shenzhen & 195 & 11 & 2251 & 36 \\
\hline & Guangzhou & 85 & 5 & 1212 & 19 \\
\hline
\end{tabular}

growth momentum in the late 1990s when the Shenzhen port began to receive calls and establish frequent services from major shipping lines such as Maersk and OOCL to major world markets such as the USA and Europe. The trend of container port regionalization has become more apparent during the first decade of the twenty-first century, with the ports in Hong Kong, Shenzhen and Guangzhou, together with a group of feeder ports, providing a multiple gateway system. Figure 4 clearly shows that the Shenzhen port, as a whole, has outperformed Hong Kong in terms of growth rate. Table 5 below simultaneously displays that the market share of Hong Kong falls from 79 to $27.9 \%$, while Shenzhen and Guangzhou's increase from 10.6, 4.6 to 36.1, $19 \%$ during 1998-2010.

Shanghai and Ningbo are the two most important ports in the Yangtze River Delta region, its spatial structure of the container port system mainly depends on the game relationship of Shanghai and Ningbo ports. Before 1840 the two ports opened to foreign traders. However, Ningbo was the only authorized port trading with Japanese. While, Shanghai port belonged to the world and developed much more rapidly. Shanghai port gradually became one of the most important hub ports in East Asia, meanwhile Ningbo port proved to be the feeder port of Shanghai. Since the late 19th, ocean shipping throughput ship sizes were getting larger, the advantage of Ningbo port's deep water was embodied. And also with the development of regional economy, more and more containers were transited through Ningbo port. Ningbo port transformed from Shanghai's feeder port to a large deepsea direct-call port. In recent years, because of Shanghai and Ningbo's physical condition, hinterland development, land condition, traffic cost and environmental pollution, Ningbo port has developed from large deep-sea direct-call port to hub port. Dualgateway becomes the spatial relationship between Shanghai and Ningbo ports. In 2010, the container throughput of two ports has achieved 29.07 and 19.04 million TEU (Fig. 5). At the same time, occupying the geographical advantage and backed by the southern Jiangsu, Suzhou port will be the third gateway of Yangtze River Delta. In short, the spatial structure of the container port system in the Pearl River Delta and Yangtze River Delta region has been getting into the 
Fig. 5 Container throughput comparison: Shanghai versus Ningbo

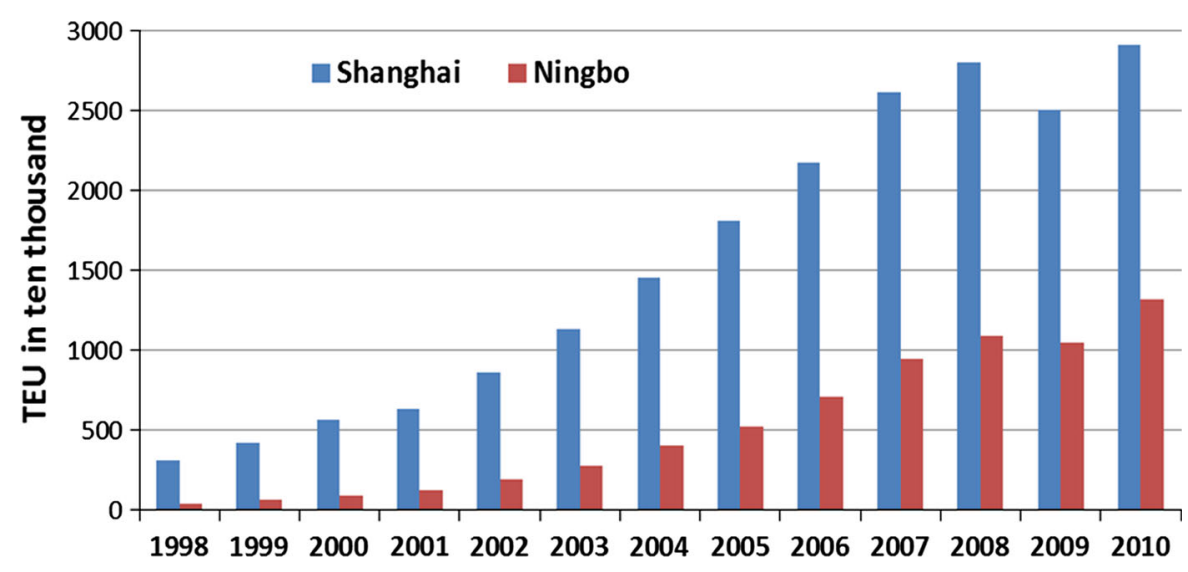

fifth stage of the Hayuth model, and multi-gateway is a distinct characteristic.

The spatial structure of rest regional is relatively simple. Southwestern coastal port range is still in a balanced development period because of later development and inadequate infrastructure, and its scale rank does not appear obvious differentiation. The Liaodong Peninsula, Bohai Sea West Bank, Shandong Peninsula and Southeast coastal port ranges are in the polarization stage. The container throughput of first ports respectively attains 5.24, 10.08, 12.01 and 5.82 million TEU, far ahead of the second ports.

\section{Reason for the new tendencies}

Quick and continuous development of economy and foreign trade

With the unbalanced development of economy and trade, international container hub port has transferred worldwidely (Fig. 6). The United Kingdom rose sharply in the first industrial revolution when its foreign trade accounted for one-fifth of the world. London has become the world's largest port and international maritime center from the beginning of the Twentieth century. To the 1950s, with the rapid economic development in the United States, New York became the most advanced container port in the world, exceeding London in aspects of port throughput, international trade, shipping status. But in 1985, container throughput in New York port, with up to 2.40 million TEU, relegated to the second place in the world, due to Rotterdam port achieved 2.65 million
TEU. However, Rotterdam port only win the first for 4 years, giving way to Hong Kong and Singapore in 1989, and from then on, Hong Kong and Singapore raised alternately. Entering the twenty-first Century, thanks to economy and foreign trade developing fast since the reform and opening up (GDP and foreign trade grew at an annual rate of 9.6 and $17 \%$ respectively, far exceeding the US, Japan, Europe and other developed countries), Chinese container throughput has achieve rapid development. In 2010, China rose to one of the international shipping centers, whose container throughput reached 140 million TEU, accounting for $25.5 \%$ of the global market. Shanghai became the world's fastest growing and largest port. Its container throughput achieved 29.1 million TEU and cargo throughput accomplished 650 million tons in 2010 .

But disparities in the growth of foreign trade in seven port range's direct hinterland has presented obviously. Since twenty-first century, the growth rate of imports and exports in southwest coast and Pearl River Delta are relatively low, while the Yangtze River Delta, Bohai Sea West Bank, Shandong peninsula have developed rapidly (Fig. 7), Such differences has prompted the center of the container port system to shift northward.

Government macro-control and policy guidance

Before the reform and opening-up policy made by the Chinese leadership of Deng Xiaoping, the national executive power played an important role in the port system evolution due to the special political and economic system. The port's planning, construction 
Fig. 6 The transfer path of world shipping center
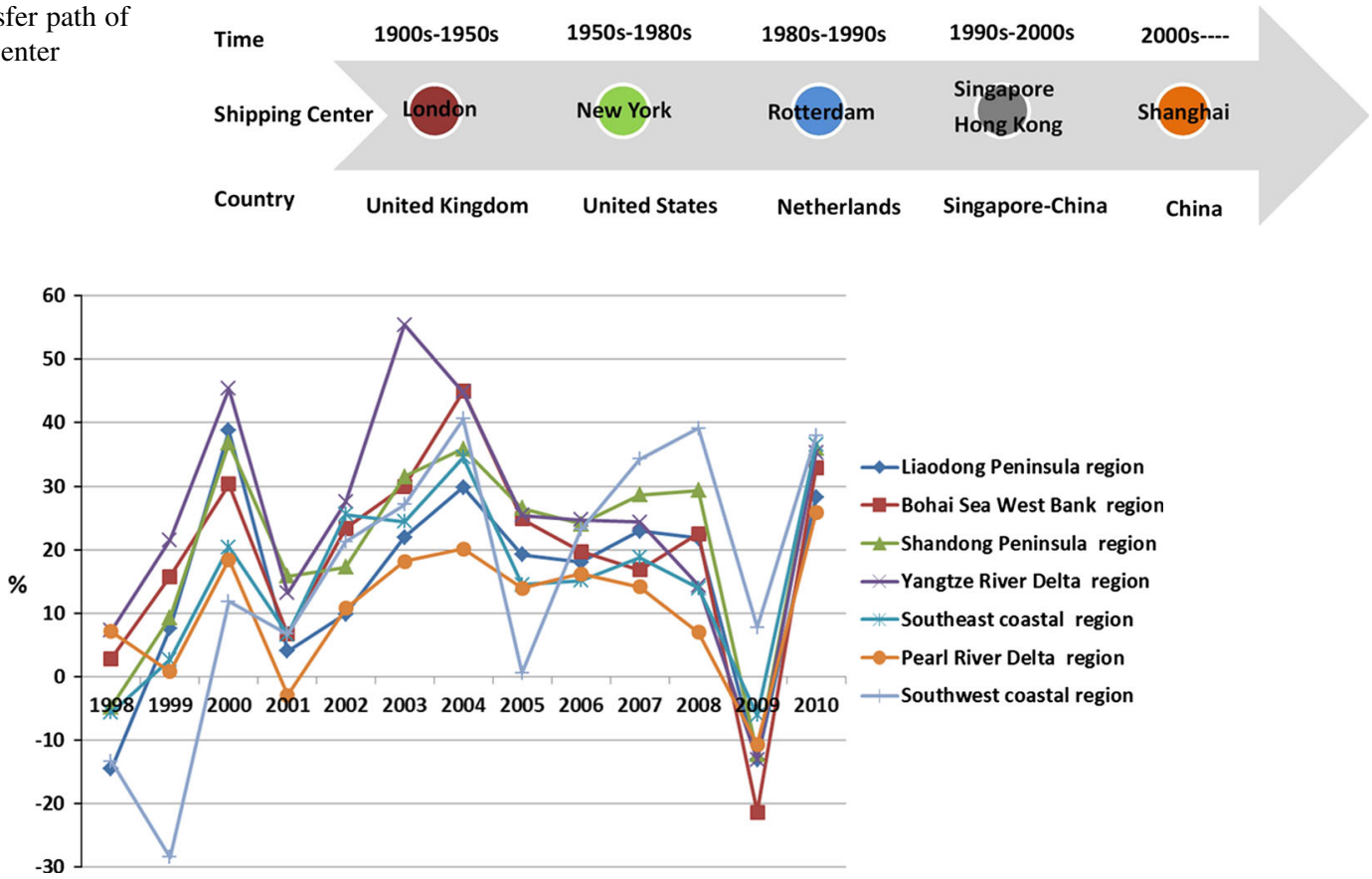

Fig. 7 The export and import growth in seven regions since 1998. Note Liaodong Peninsula region: Liaoning province. Bohai Sea West Bank region:Tianjin, Hebei province. Shandong Peninsula region: Shandong province. Yangtze River

and management is highly concentrated, so that its development level is terribly restrictive. During the same period, lack of container deep-water coastline, ships and port facilities etc., the Chinese mainland cargo must transit through Hong Kong to go around the world. The container throughput of Hong Kong has grown rapidly, and gradually become an important gateway for Chinese foreign exchange. Between the 1980s and 1990s, with the devolution of port management to local government, and the management mode of "double leadership of the local government and central government, priority to local government" was formed, port investment and construction fields were gradually opened up, it fully mobilize the resources to port construction such as the local government, private enterprise, free capital. Meanwhile, in order to avoid disorderly competition among container ports, the central government gave priority to construct the main hub. In this context, Shanghai developed rapidly. To 2000, the container throughput of Shanghai reached 5.61 million TEU, ranked the sixth in the world, and became the real sense of the world hub port after Hong Kong.
Delta region: Shanghai, Zhejiang, Jiangsu province. Southeast coastal region: Fujian province. Pearl River Delta region: Hong Kong, Guangdong province. Southwest coastal region: Hainan, Guangxi province

Entering the twenty-first century, influenced by sustained growth of import and export goods, capacity limitations of hub port, the central government begins to introduce a series of policies to support peripheral ports which own excellent conditions, such as Setting up Ningbo Meishan Free Trade Port Zone, Shenzhen Qianhai Bay Bonded Port Area, Guangzhou Nansha bonded port area and approval of Ningbo-Zhoushan port combination. On the other hand, the central government gives impetus to Hong Kong and Shanghai port transformation, which focus on developing shipbrokerage, shipping finance, ship registration, maritime arbitration, and builds a real international financial center and shipping center. These not only promote the original hub upgrading, but also create new gateways.

The challenge of the periphery

With the improvement of the spatial organization of the container port system, peripheral challenges began to appear (Hayuth 1981, 1988). The land limitations, shoreline shortages, rising costs, traffic 
Table 6 The comprehensive comparison among Hong Kong, Shenzhen and Guangzhou ports

\begin{tabular}{lllll}
\hline Item & Indicator & Hong Kong & Shenzhen & Guangzhou \\
\hline Infrastructure level & Water depth & -15 & -16 & -13 \\
& Berthing capability (10,000-ton) & $5-8$ & $5-8$ & 5 \\
& Transportation cost & High & Medium & Low \\
& Operating facilities & High & High & Medium \\
Service level & Information service & High & Medium & Medium \\
& Port charges & High & Middle & Low \\
& Port environment & High & Medium & Medium \\
& Finance and logistics & High & Medium & Low \\
\hline
\end{tabular}

congestion and environmental constraints restrict the development of few large hubs, their growth rate slows down significantly. On the other hand, because of better operational conditions, many peripheral ports develop fasterly; the decentralization of container flow starts to appear in an area. The early twenty-first century, the coastline utilization ratio of Huangpu River and Liuhekou-Wusongkou has reach up to 89.5 and $82.4 \%$, shoreline becomes scarce resource, and its use-cost grows clearly. Meanwhile, the Huangpu River waterway with only $-7 \mathrm{~m}$ depth at low tide cannot meet the need of large container vessels' entering and leaving the port; and the problem of the traffic jams in the hinterland, high cost and low efficiency of highway container transportation are also prominent. The same problem exists in Hong Kong, after 40 years of construction; the container shoreline has been used up now. Furthermore, the land cost, staff salaries and operating charges are significantly higher than Shenzhen and Guangzhou. In recent years, because of having more surplus land, environmental capacity, water depth and shoreline conditions, Ningbo, Shenzhen, Guangzhou and other peripheral ports have developed faster than Shanghai, Hong Kong and other hubs. In some ways, they have already approached, or transcended Hong Kong and shanghai ports (Table 6).

Network expansion of shipping liners and terminal operators

In the planned economy period, the Chinese central government monopolized the investment and construction of the port in China, so that port handling capacity cannot meet the market demand. In order to overcome such drawback, government began to promote the reform so that it can realize diversified sources of investment from 1984.

In 1987, Nanjing and Tianjin Port set up joint venture with container operation, it marked the beginning of diversification in port investment; In 1993, the Ministry of Transportation promulgated "the Several Opinions on Deepening the Reform, Expanding Opening-up, Accelerating Transportation Development", and encouraged domestic and international enterprise to set up sino-foreign joint venture to construct and operate public docks and berths. Container transportation has taken the lead to achieve the breakthrough, especially in the 1990s, the topping terminal operators at home and abroad have begun to expand their service network like Hutchison Port Holdings (HPH), COSCO, China Shipping, PSA and APM Terminals (Table 7).Currently, the major coastal ports, like Dalian, Qinhuangdao, Tianjin, Qingdao, Shanghai, Ningbo, Fuzhou, Xiamen, Shantou, Shenzhen, Guangzhou, Zhuhai, and the main Yangtze River ports, as Nanjing, Zhangjiagang, Changshu, Taicang all have jointly invested or solely foreign-funded container terminals, the number of joint venture docks have reach to $64.2 \%$, and its completed container throughput accounted for $2 / 3$ of China.

At the same time, large quantities of goods in China prompt the international shipping companies to adjust global shipping network such as Maersk, MSC, CMACGM, Hapag-Lloyd, Evergreen, APL, OOCL, YML, HMM, and build the new network that call directly Chinese ports. Now the Hong Kong, Shanghai, Ningbo and Shenzhen have integrated into the global trunk 
Table 7 The network expansion of renowned terminal operators in China

\begin{tabular}{|c|c|}
\hline $\begin{array}{l}\text { Terminal } \\
\text { operators }\end{array}$ & Port investment and time \\
\hline COSCO Group & $\begin{array}{l}\text { Qingdao (1995/2000), Taicang (1998), } \\
\text { Shanghai (2003), Ningbo (2003), } \\
\text { Yingkou (2004), Tianjin (2005), Nanjing } \\
\text { (2005), Quanzhou (2006), Guangzhou } \\
\text { (2006) }\end{array}$ \\
\hline China Shipping & $\begin{array}{l}\text { Shenzhen (1999), Shanghai (2000), Jinzhou } \\
\text { (2001), Yantai (2003), Guangzhou } \\
\text { (2003), Tianjin (2005), Yingkou (2007), } \\
\text { Dalian (2007), Qinhuangdao (2007), } \\
\text { Lianyungang (2007) }\end{array}$ \\
\hline $\mathrm{HPH}$ & $\begin{array}{l}\text { Zhuhai (1992), Shenzhen (1993), Shanghai } \\
\text { (1993/2003/2005), Xiamen (1997), } \\
\text { Ningbo (2001) }\end{array}$ \\
\hline $\begin{array}{l}\text { China } \\
\text { Merchants } \\
\text { Group }\end{array}$ & $\begin{array}{l}\text { Zhangzhou (2000), Shenzhen (1989), } \\
\text { Ningbo (2003), Tianjin (2005) }\end{array}$ \\
\hline $\begin{array}{l}\text { PSA } \\
\text { International }\end{array}$ & $\begin{array}{l}\text { Dalian (1996/2004), Tianjin (2005), } \\
\text { Fuzhou (1998), Guangzhou (2003) }\end{array}$ \\
\hline APM Terminals & $\begin{array}{l}\text { Guangzhou (2001), Ningbo (2003), Tianjin } \\
\text { (2005), Xiamen (2006) }\end{array}$ \\
\hline
\end{tabular}

Source China Ports Yearbook, 2011

network. With the influx of international shipping liners and terminal operators and its network expansion, the gap between Chinese ports and oversea ports is closing; besides, the hubs have gradually narrowed the gap with the periphery.

\section{Conclusion}

In this paper, Chinese container port system is divided into seven parts, which is different from three parts as Yangtze River Delta, Pearl River Delta and Bohai Rim port systems. We quantitatively measure the spatial structure and new tendency of Chinese container port system; analyze the formation mechanism of multiport gateway from container flow by $\mathrm{HHI}$ in 1998-2010. Research shows that Chinese container ports have developed rapidly, and stepped into "peripheral challenge" stage in a whole. Decentralization has become the main line of the container port system in accordance with the fifth stage of the Hayuth model for more than decade, like as the Yangtze River Delta port system and Pearl River Delta port system. This phenomenon is the same as the Europe, United
States and South Korea. But the Chinese container port system presents another unique characteristic, which is the coexistence of diverse spatial structure, such as low-level equilibrium, single-gateway and multi-gateway. Multi-gateway ports region of container port system that formed in Yangtze River Delta and Pearl River Delta region is the most prominent space features. Trade development, government guidance, peripheral challenge and the service network expansion of the shipping liners are the main driving forces.

Acknowledgments This research is supported by the Natural Science Foundation of China (Project No. 41271136, 41301126).

Open Access This article is distributed under the terms of the Creative Commons Attribution License which permits any use, distribution, and reproduction in any medium, provided the original author(s) and the source are credited.

\section{References}

Cao, Y. H., Li, H. J., \& Chen, W. (2004). The spatial structure and the competition pattern of the container port system of China. Acta Geographica Sinica, 59(6), 1021-1027. (In Chinese).

Cheung, R. K., Tong, J. H., \& Slack, B. (2003). The transition from freight consolidation to logistics: The case of Hong Kong. Journal of Transport Geography, 11(4), 245-253.

Comtois, C., \& Dong, J. (2007). Port competition in the Yangtze River Delta. Asia Pacific Viewpoint, 48(3), 299-311.

Cullinane, K., Teng, Y., \& Wang, T. F. (2005). Port competition between Shanghai and Ningbo. Maritime Policy \& Management, 32(4), 331-346.

Ducruet, C., Notteboom, T., et al. (2009). Revisiting inter-port relationships under the new economic geography research framework. In T. Notteboom, C. Ducruet, \& L. P. De (Eds.), Ports in proximity: Competition and coordination among adjacent seaports (pp. 11-28). Alderschot: Ashgate.

Frémont, A., \& Soppé, M. (2007). Northern European range: shipping line concentration and port hierarchy. In J. Wang, T. Notteboom, D. Olivier, \& B. Slack (Eds.), Ports, cities and global supply chains (pp. 105-120). Alderschot: Ashgate.

Hayuth, Y. (1981). Containerization and the load center concept. Economic Geography, 57(2), 161-176.

Hayuth, Y. (1988). Rationalization and deconcentration of the US container port system. The Professional Geographer, 40(3), 279-288.

Liu, L. M., Wang, K. Y., \& Yip, T. L. (2013). Development of a container port system in Pearl River Delta: path to multigateway ports. Journal of Transport Geography, 28, 30-38.

Notteboom, T. (2005). The peripheral port challenge in container port systems. In H. Leggate, J. Mcconville, \& A. Morvillo (Eds.), International maritime transport: perspectives (pp. 173-188). London: Routledge. 
Notteboom, T. (2010). Concentration and the formation of multi-port gateway regions in the European container port system: an update. Journal of Transport Geography, 18(4), 567-583.

O'Connor, K. (2010). Global city regions and the location of logistics activity. Journal of Transport Geography, 18(3), 354-362.

Scherer, R. M. (1980). Industrial marketing structure and economic performance. Chicago: Rand McNally College Publishing Company.

Slack, B. (1990). Intermodal transport in North America and development of inland load center. Professional Geographer, 42(1), 72-83.

Slack, B., \& Wang, J. J. (2002). The challenge of peripheral ports: An Asian perspective. GeoJournal, 65(2), 159-166.

Song, D. W. (2002). Regional container port competition and co-operation: The case of Hong Kong and South China. Journal of Transport Geography, 10(2), 99-110.

Taaffe, E. J., Morrill, R. L., \& Gould, P. R. (1963). Transport expansion in underdeveloped countries: A comparative analysis. Geographical Review, 53(4), 503-529.

Tongzon, J. (2006). Singapore and Tanjung Pelepas: Co-operation or competition? In K. Cullinane, D.-W. Song (Eds.), Asian container ports. Development, Competition and Cooperation. Basingstoke, UK.

Wang, C. J., \& Ducruet, C. (2012). New port development and global city making: emergence of the Shanghai-Yangshan multilayered gateway hub. Journal of Transport Geography, 25, 58-69.
Wang, C. J., Wang, J. E., \& Ducruet, C. (2012). Peripheral challenge in container port system: A case study of Pearl River Delta. Chinese Geographical Science, 22(1), 97-108.

Wang, J. J. (1998). A container load center with a developing Hinterland: A case study of Hong Kong. Journal of Transport Geography, 6(3), 187-201.

Wang, J. J., \& Cheng, M. C. (2010). From a hub port city to a global supply chain management center: A case study of Hong Kong. Journal of Transport Geography, 18(1), 104-115.

Wang, J. J., \& Oliver, D. (2007a). Shanghai and Ningbo: In search of an identity for the Chanjiang Delta region. In K. Cullinane, \& D.-W. Song (Eds), Asian container ports. Development, Competition and Co-Operation (pp. 183-197). Basingstoke, UK: Palgrave McMillan.

Wang, J. J., \& Olivier, D. (2007b). Hong Kong and Shenzen: The Nexus in South China. In K. Cullinane, \& D.-W. Song (Eds.), Asian container ports. Development, Competition and Co-operation (pp. 198-212). Basingstoke, UK: Palgrave McMillan.

Wang, J. J., \& Slack, B. (2000). The evolution of a regional container port system: The Pearl River Delta. Journal of Transport Geography, 8(4), 263-275.

Yeo, G. T., \& Cho, S. H. (2007). Busan and Gwangyang: One country, two port system. In K. Cullinane, \& D.-W. Song (Eds.), Asian container ports. Development, Competition and Co-Operation (pp. 225-238). Basingstoke, UK: Palgrave McMillan. 